\title{
Leadership Management of Military Hospital in Efforts to Improve the Patient Service (Case Study of RSAL Dr. Mintoarjo)
}

\author{
Radito Soesanto \\ Doctorate Student, Human Resource Management, \\ the State University of Jakarta, Indonesia \\ E-Mail: arraditoindo@yahoo.com \\ Hady Efendy (Corresponding Author) \\ Education Practice and Academic Consultant, Indonesia \\ E-mail: efendy_hady@yahoo.co.id
}

Received: Oct. 25, 2017 Accepted: Nov. 14, 2017 Online published: Nov.15, 2017

doi:10.5296/ijhrs.v8i1.12055 URL: https://doi.org/10.5296/ijhrs.v8i1.12055

\begin{abstract}
RSAL dr. Mintoharjo is a military hospital serving members of the Indonesian National Army, the Navy and their families also provide services to the general public. Utilization of hospital facilities has not been optimal with the standard value of Bed Occupancy Rate (BOR) below the minimum value that must be achieved. Leadership becomes one of the factors that greatly affect the organization. A leader plays an important role because its existence can determine the progress of the organization, with the change of hospital leadership is expected for better organizational performance. Better performance is one of them by providing good service to the customer so customer satisfaction will be improved so that will reduce (save) cost to effort to attract new customer. In an effort to improve the quality and service of RSAL dr. Mintoharjo implements effective leadership strategies, Transformative and militaristic leadership styles and innovatively transforms organizational culture. With an effective leadership strategy. RSAL dr. Mintoharjo has a strategy of building service, human, quality and achievement in finance. Building service by choosing superior service included in hospital vision, mission, values and strategic plan. Building humanity and quality is by building leadership and training institutions. In the field of finance has been built Hospital Management Information System (SIMRS) is very helpful in the management of hospital
\end{abstract}


finances. With an effective leadership strategy and leadership style of the Military Transformational Head of RSAL dr. Mintoharjo managed to change the existing organizational culture in the Hospital to be better one of them is with the measuring value of the increasing number of BOR RSAL dr. Mintharjo.

Keywords: bed occupancy rate, military hospital, leadership, management

\section{Introduction}

Military Hospital RSAL dr. Mintohardjao (RSAL Dr. MTH) in Jakarta is a hospital (RS) that can be categorized by type or management is a Military Hospital that serves members of the Indonesian National Army (TNI) and the Indonesian Navy and their families as well serving for the General. Under the leadership of the old Hospital Head, the utilization rate of hospital facilities in RSAL dr. Mintoharjo is still not optimal. BOR (Bed Occupancy Rate) or percentage indicating the average of beds used every day that existed so far is still below the standards that should be achieved. BOR is calculated by the formula of the total number of treatment days of the total inpatient in a year divided by the number of existing beds, the result divided by the number of days in the year and expressed in the presentation. The ideal value or ideal number that should be achieved is 60-85\%. (Ministry of Health Republic of Indonesia 2005) The value of this standard resulted from the comparison between the numbers of patients staying with the total hospital operational costs.

It appears that the average BOR at RSAL dr. Mintoharjo of $40,85 \%$. This value is smaller than the value of the BOR should be (referring to Barber Johnson Graph the value of BOR is $60-85 \%)$. The low level of BOR achieved actually illustrates that the service quality of the hospital concerned is low. One of the reasons for the low value of BOR is the low quality of service in the hospital. Patients or prospective patients tend to be reluctant to stay longer if they feel treated less professionally. For patients who have received treatment at the hospital, it is whether or not he was staying can depend on the illness experienced. However, low quality of services provided can also reduce the interest of other prospective patients to choose hospitalization in the hospital. Patients generally prefer to be hospitalized to provide good services. This condition illustrates why the low BOR can be caused by the low service provided. Therefore, as a consequence, if the BOR rate is low then the management of the hospital concerned should improve the quality of service to the patient, especially for those who are in hospital (Suryadi, 2001).

It takes the leadership of a vision-oriented Head Hospital to transform leadership strategies, leadership styles, and change organizational culture by improving patient care, improving the quality of patient care in the organization of hospital services, the hospital can make efforts to improve the quality of public and medical services. By doing innovative breakthrough leadership will make the service excellence and satisfaction of patients, employees and doctors so that the increase of BOR Hospital will be achieved.

\subsection{Problem Formulation}

Based on the conditions that occurred in RSAL dr. Mintoharjo, Suryadi (2001) explained that one of the efforts that can be done by the hospital to improve its performance is by improving 
the quality of service given to its patients.

The formulation of the problem in this paper is:

1. How is the implementation of the current leadership strategy in the hospital?

2. What is the current applied leadership style in the hospital?

3. How does leadership build an organizational culture around hospital service issues?

\subsection{Research Methods}

The method taken in this research is: study the library and observe to the location where the research. By looking at document studies, and the results of previous research and looking directly into the object of research. The purpose of this study: to see how far the importance of TNI hospital management system to the acceleration of service for the welfare of TNI soldiers.

A. Problems:

1. What are the obstacles and obstacles that reduce the acceleration of Military Hospital services to patient care?

2. Which strategies are appropriate to speed up the service?

B. Purpose of Writing

1. Analyze the implementation of current leadership strategies in hospitals?

2. Analyzing the current applied leadership style in the hospital?

3. Analyzing leadership by building an organizational culture around hospital service issues?

\section{Literature Review}

\subsection{Leadership}

From several sources leadership is defined differently. For example say that:

1. Leadership is a management tool. Managers exercise leadership to influence staff to achieve previously planned organizational goals.

2. Leadership is a process of influencing others in order to achieve certain goals.

3. Leadership is a complex social phenomenon that is influenced by a number of personal, interpersonal, and organizational factors that include the personal qualities of leaders, leader behavior, and situational factors.

In the Journal The relationship between perceived leadership style and perceived stress on hospital employees is defined as leadership, good leadership is important for the success of health organizations, leadership topics have been interesting for hundreds of years and many scientists have tried to make leadership definitions. Bennis (2009) explains that leadership is like a beauty: "it is difficult to determine, but when you see it." Before the 1980s the main approach to leadership was the nature, style, and contingency approach. Since the early 1980s new leadership (including charismatic leadership / transformational) has been seen.

The first principle in leadership is the relationship between leader and leader. Without that led 
no one needs to lead. The second principle is that effective leaders recognize and manage consciously the dynamics of relationships between leaders and those led according Richard Beckhard. Conception of leadership cannot be separated from ability, authority, and power. A leader, because his status and duties must have power. Power is the capacity to unilaterally affect people's attitudes and behaviors in the desired direction (Gary Yukl, 2001).

In a slightly different language, Kartini Kartono (2016) reveals that the source of a leader's power can come from:

1. His ability to influence others;

2. His superior attributes and attitudes, thus having authority over his followers;

3. Have extensive information, knowledge, and experience;

4. Have good human relation skills, intelligence and communication.

\subsection{The Influence of Leadership on Service Behavior}

Various management literature explains that leadership becomes one of the factors that greatly affect the organization. A leader plays an important role because his existence can determine the organization's progress.

Research results from Church (1995) also indicate a positive influence between leadership and employee service behavior. The research that discusses the impact of leadership behavior on employee service performance resulted in the finding that leadership behavior directly affects the quality of employee service which in turn will bring positive impact on the improvement of organizational performance.

\subsection{The Influence of Service Behavior on Organizational Performance}

The relationship between service behavior variable and organizational performance intuitively can be understood. Because anyhow by providing good service to customers then customer satisfaction will be improved. Meanwhile, satisfied customers will be able to reduce (save) cost for efforts to attract new customers. Because actual efforts to attract new customers will not happen if customers feel satisfied. This is due to the satisfaction that arises from the old customers will be a means of promotion for potential new customers.

In addition, the provision of quality services to customers will allow the company to maintain or even improve transactions with existing customers, which also means the reduced likelihood of losing or switching old customer loyalty to other organizations. It is therefore reasonable that some previous studies have consistently shown that quality services are found to result in higher financial performance (Zeithaml in Chang and Chen 1998).

\subsection{Effective Leadership Strategy}

Effective leadership is not just a center of position or power, but also an active interaction between effective components. Here are some effective leadership strategies to develop the company, among others:

1. Have a vision

2. Be a good example of behavior so that employees can take examples of such behavior. 
3. Be a good communicator

4. Become a manager in the field of good finance

Effective leaders and organizations have the following characteristics:

1. Able to exploit and use environmental resources to maintain the continuity of organizational functions.

2. Able to achieve / realize organizational goals that may be many, varied, different and even contradictory.

3. Able to meet the needs of individuals or groups.

4. Able to make adjustments to environmental demands.

5. Be able to formulate goals and mobilize resources to achieve them

6. Be able to integrate (organize, co-ordinate, unite interrelated members.

7. Able to maintain and maintain the sustainability of cultural patterns and organizational motivation.

8. Able to face environment, goals, members, plural choices and potential conflicts.

\subsection{Leadership Style}

Leadership style is a set of characteristics that leaders use to influence subordinates to achieve goals or patterns of behavior and strategy that is liked and often applied a leader. Here are some different styles of leadership:

1. Charismatic leadership style, is a leadership style that is able to attract the attention of many people.

2. Authoritarian leadership style, is the style of leader who decides all decisions and policies taken from himself fully.

3. The style of leadership is the leadership style of a leader will be different, depending on what level of readiness of followers

4. Militaristic leadership style: in this type of leader possesses the following characteristics:

a. More in using command or command system

b. Wants absolute obedience from subordinates

c. Loved the formalities

d. Demanding a harsh and rigid discipline from below

e. Do not want suggestions, suggestions, suggestions and criticism of subordinates

\subsection{Conception of Transformational Leadership}

The concept of transformational leadership was first put forward by James McGregor Burns. In relation to transformational leadership, Bernard Bass says the following: "Transformational leaders 'transformation of the organization's personal and environmental concerns by fostering an environment in which visions can be shared ". From some of these terms transformational leadership is a style of leadership that seeks to transform the values embraced by subordinates to support the vision and goals of the organization. Through the transformation of these values, it is expected that good relations between members of the organization can be built so that there is a climate of trust among members of the organization. 
A leader is said to be transformational when it can change the situation, change what is commonly done, talk about a lofty goal, have a reference to the value of freedom, justice and equality. The transformational leader will make the subordinate see that the goal he wants to achieve is more than just his personal interests. Meanwhile, according to Yukl (2001), transformational leadership can be seen from the high commitment, motivation and trust of subordinates so that the organization's goal is to achieve more than just his personal interests.

Meanwhile, based on the results of Devanna \& Tichy's research the characteristics of transformational leaders can be seen from the way leaders identify themselves as change agents, encourage courage and risk-taking, believe in people, as lifelong learners, have the ability to overcome complexity, ambiguity, and uncertainty, also a visionary leader.

The characteristics of transformational leadership according to Avolio et al (Stone et al. 2004) are as follows:

1. Idealized influence (or charismatic influence)

Idealized influence has the meaning that a transformational leader must be charisma capable of "bewitching" subordinates to react to the leadership. In other words, transformational leaders become role models that are admired, valued, and followed by their subordinates.

2. Inspirational motivation

Inspirational motivation means the character of a leader who is capable of applying a high standard but also able to encourage subordinates to achieve the standard. Such characters are able to generate optimism and high enthusiasm from their subordinates. In other words, transformational leaders always inspire and motivate their subordinates.

3. Intellectual stimulation

Intellectual stimulation character of a transformational leader who is able to encourage his subordinates to solve problems carefully and rationally. In other words, transformational leaders can encourage (stimulate) subordinates to always be creative and innovative.

4. Individualized consideration

Individualized consideration means the character of a leader who is able to understand the individual differences of his subordinates. In other words, transformational leaders are able to understand and appreciate subordinates based on the needs of subordinates and pay attention to the desire of prentice and develop the subordinates.

\subsection{Characteristics of the Visionary Leader Needed}

Visionary leader according to Nasir (2012) as follows:

1. Insight into the Future

2. Dare to Act in Obtaining Goals - Full of confidence, no doubt and always ready to take risks, careful, thorough, and accurate.

3. Able to Raise Others - Have the ability to raise others for hard work and cooperation in reaching the goal.

4. Being able to Formulate Vision - Inspirational and inspiring, Visionary Leader is a person who has a strong commitment to his vision 
5. Able to Change Vision into Action - A visionary leader can formulate a vision into his mission which can then be absorbed by members of the organization or community he leads.

6. Closely Hold to Spiritual Values - The visionary leaders are very professional to what is believed, like the noble values that exist in this nation

7. Building Relationships Effectively - The visionary leader must be very good at building relationships between members or between communities in a larger scoop, in terms of motivating, giving, making members or the community more advanced and independent.

8. Innovative and Proactive - In thinking, the visionary leader is very creative. He was able to change something conventionally into a new paradigm, he was a creative and active leader.

\subsection{Organizational Culture}

Organizational culture is the basic philosophy of an organization that creates shared beliefs, norms, and values that characterize the core of how to do something in the organization. Organizational culture is indispensable and crucial to achieving the organization's top performance. Yet Organizational Culture must always move, change, and transform the organization's needs in response to strategic environmental change.

Leaders always present a new organizational culture every day with what they do. The behaviors they show, the wisdom they make up, the emotions they express or emphasize, the commitment they show, the attitude in communication, and the values from which they live, all affect the attitudes and behaviors of the organization

\section{Discussion}

\subsection{Current Hospital Leadership Conditions}

\subsubsection{Current Leadership Strategy}

The current leadership strategy has not made service and care the first leading role in hospital development. The current strategy is the concept of improving the advanced technology in service delivery to patients. By preparing hospital health equipment expected patient will get the best service.

In building hospital service, hospital leaders have not been able to exploit and use environmental resources to maintain the continuity of organizational function, not giving priority to patient satisfaction and quality of care. The hospital leader does not become a good communicator to the management officers, employees, nurses, doctors, patients and patient families. Implementation of the communication program has not been scheduled well especially about the definition of excellence Hospital.

In building human resources, there are no programs in the improvement in the field of leadership to the heads of departments, heads of departments, heads of nursing and head of nursing space that can serve as a catalyst for organizational change.

In the development of quality human resources training and coaching on all employees 


\section{Macrothink}

International Journal of Human Resource Studies

ISSN 2162-3058

2018, Vol. 8, No. 1

Hospital carried out by development, education and training without touching the quality improvement hospital. In the financial sector still uses a manual system that relies on conventional financial officers.

\subsubsection{The Leadership Style Applied in Leading RSAL Dr Mintoharjo at Present}

The current leadership style cannot influence subordinates for the objectives and goals achieved by the hospital that can increase the value of BOR from the hospital. In improving the BOR hospitals are needed leaders of creative and innovative and have a commitment, motivation and high confidence in achieving organizational goals that can stimulate all employees and organizations in running the vision, mission of RSAL dr. Mintoharjo.

The current leadership style is felt more toward militarized authoritarian leadership: in this type of leader the qualities of: More in using the command or command system, wanting the absolute obedience of subordinates, favors formality, demands a harsh and rigid discipline from the bottom, no requires suggestions, suggestions, suggestions and criticism of subordinates and decide all decisions and policies taken from himself in full.

The militaristic leadership style sometimes causes discomfort among non-military employees, for example from civil servants and honorary employees, sometimes causing the hurt of some employees to get orders from the head of hospital. The nature of communication sometimes only one-sided caused the disappointment of some employees.

3.1.3 Current Leadership in Building an Organizational Culture around Hospital Service Issues?

Leaders today are less listening to problems that occur in hospitals and often reject the suggestions and ideas of subordinates. Leaders are slow to innovate, slow to make decisions. Leaders are currently less developed employees and satisfied with himself.

\subsection{Hospital Leadership Condition Expected}

\subsubsection{Leadership Strategy Expected}

In leader of RSAL dr. Mintoharjo is making RSAL dr. Mintoharjo to be the best of the best by providing services and care not only good but very special to the patient.

Leader of RSAL dr. Mintoharjo has a strategy of building:

1. Service

2. Man

3. Quality

4. Achievements in finance.

Building service:

1. RSAL dr. Mintoharjo provide excellent service and care that is by choosing service excellence. Hospital brings nursing consultants to nurse's employees and nurses to improve patient satisfaction and quality of patient care. 
2. To achieve these advantages leaders of RSAL dr. Mintoharjo incorporated it into the hospital's vision, mission, values and strategic plans. In the vision of entering the word of excellence and trustworthy service, in the mission to include excellence in care, the values are also included the word of excellence, as well as service excellence made Strategic Plan Hospital.

3. The next strategy is to create bulletins or newsletters for employees, volunteers, and doctors, create banners, posters and sheets.

4. Forum employees led by hospital leaders to communications can be established between the management hospital and the employees.

5. Presentation of leadership issues is done on a scheduled basis in the meeting activities in the scope of parts or units.

6. Competition is held which all employees follow on the understanding of the superiority of the goal is for leaders, staff, employees, and doctors to see that RSAL dr. Mintoharjo works towards excellence in every part of the hospital.

Building human beings:

1. Build a leadership institution that aims to teach both old and new leaders new skills, abilities, and behaviors that can help them become better leaders and serve as a catalyst for organizational change.

2. RSAL dr. Mintoharjo also recognizes and rewards employees for their achievements and performance, for example every RSAL dr. Mintoharjo anniversary will be announced by the exemplary employees and they will get the charter and the prize, each room of the month will be announced monthly employees and their photos will be posted in the receiving room of each unit. Every Monday when the morning apple will be announced the best employees and received praise from the leadership.

3. RSAL dr. Mintoharjo in addition to awarding also provides disciplinary punishment to employees who make mistakes. Provision of punishment is given as learning for all employee members.

Building quality:

1. That is with training needs analysis:

a. Analysis based on hospital's strategic needs in achieving excellence in patient care and care.

b. Analysis based on competence, according to position and position. Each position and position is able to manage primarily in patient care

c. Analysis based on competence level that is completeness of certification requirement.

2. Achievements in the field of finance

Head of hospital develop Hospital Management Information System (SIMRS) is an integrated information system that is prepared to handle the whole process of management of the hospital, one of the modules integrated in this system is a financial problem. This is very helpful in financial management and also can avoid leakage in the field of finance.

3.2.2 The Leadership Style Expected in Leading RSAL Dr. Mintoharjo 


\section{MInstitute Machink $_{\text {Insthe }}$}

Transformational leadership style and visionary is a leadership style that seeks to transform the values shared by subordinates to support the vision and goals of the organization. A leader is said to be transformational when it can change the situation, change what is commonly done, talk about a lofty goal, have a reference to the value of freedom, justice and equality. The transformational leader will make the subordinate see that the goal he wants to achieve is more than just his personal interests.

Head of RSAL dr. Mintoharjo has a high commitment, motivation and trust of subordinates to see the goals of the organization to be achieved more than just his personal interests. In addition, it can stimulate the spirit of employees and doctors to see their work from several new perspectives. Head of hospital can lower vision and mission to all employees and organization in hospital with full confidence and assure that the vision and mission can be achieved even though many believe that to achieve vision and mission without supported by technology of sophisticated health equipment will be difficult successful.

Communication to employees, nurses, management, doctors, patients and patient families is very good and is formed independently and naturally. In giving rewards to subordinates without any shame spontaneously will give praise and certainly a reward for the good work of each subordinate. But in giving punishment is also without a doubt.

Creative and innovative ways of thinking are included in the application of organizational change models that have the principle of achieving excellence and being the best of good, building a culture of champion that is embedded in all employees. Changing the way in which service to the patient and his family makes the patient's ultimate satisfaction in service. Establish working standards (performance) in support of hospital mission and vision.

Building the responsibility of the employees for all actions taken either individually or team. Recognition and respect for employees and attention to physician satisfaction. Monitoring all that always done measurements in the form of patient satisfaction surveys every week, month and year, and continue to conduct leadership training so that the momentum of success can be maintained.

All success is achieved there is also imperfection in terms of existing leadership. Head of RSAL dr. Mintoharjo is a military physician who, since joining the Army-Navy, has long served in the army, with a military background he also has a militaristic type of leader, which has a hard and rigid discipline, every order must be immediately undertaken by subordinates, sometimes excessive formality and communication is sometimes only one-sided.

This militaristic nature sometimes causes discomfort among non-military employees, sometimes causing the hurt of some employees to get orders from the head of the hospital. The nature of communication sometimes only one-sided caused the disappointment of some employees. However, behind this militaristic nature there is a positive aspect in achieving mission objectives and vision of the Hospital because it creates the prestige and charisma arising from this militaristic attitude. 


\subsubsection{Hospital Leadership Builds an Expected Organizational Culture}

As a government hospital where the technology purchase budget is very limited then the Head of RSAL dr. Mintoharjo must find a gap to keep on achieving success. The mission that can be done by the Hospital is by excellence on patient care.

Building a culture around the problem by:

1. Behavior standards, to provide clear restrictions on what to expect from employees by emphasizing Hospital values and dealing with things like interpersonal communication, working well with partners, personal appearance and privacy for patients.

2. The establishment of a team of customer satisfaction and physician satisfaction.

3. Prioritizing nurse leaders to conduct mobile visits to patients, families, and staff within their respective work units. And the hospital leader or representative represents a Rounding visit to all work units or patient nursing rooms on a Monday.

4. Build communication tactics that is biased through leadership meetings, employee forums, e mail or WhatsApp and employee bulletins.

5. Leaders appreciate the difference between superiors and subordinates. Opportunities will come to welcome differences of opinion and ideas by mutual respect.

6. The existence of mutual trust between human resources in the organization, either between the leadership with subordinates and among fellow co-workers.

\section{Conclusion}

RSAL dr Mintoharjo is a military hospital that serves members of the military's and its families also serve the general public, under the leadership of the previous Head of Hospital utilization of hospitals facilities not optimal with the standard value of Bed Occupancy Rate (BOR) under minimum standards to be achieved. Leadership becomes one of the factors that greatly affect the organization. A leader plays an important role because its existence can determine the progress of the organization, with the change of hospital leadership is expected for better organizational performance. Better performance is one of them by providing good service to the customer then the customer satisfaction will be improved. Meanwhile, satisfied customers will be able to reduce (save) cost for efforts to attract new customers. By attracting new customers is expected to increase BOR Hospital. With an effective leadership strategy. RSAL dr Mintoharjo has a strategy of building service, human, quality and achievement in finance. Building service by choosing superior service included in hospital vision, mission, values and strategic plan. Building humanity and quality is by building leadership and training institutions. In the field of finance has been built Hospital Management Information System (SIMRS) is very helpful in the management of hospital finances. Transformational leadership style visionary and backed up as military doctors who have the character of leadership militaristic Head of RSAL dr. Mintoharjo is able to attempt to transform the values held by subordinates to support the vision and goals of the organization. With an effective leadership strategy and leadership style of the Military Transformational Head of RSAL dr. Mintoharjo managed to change the existing organizational culture in the Hospital to be better one of them is with the measuring value of increasing the number of BOR RSAL dr. Mintoharjo. 


\section{Suggestion}

From these conditions, where there are still obstacles in the implementation of the pattern of leadership development RSAL dr. Mintoharjo, the following matters may be suggested:

a. It is necessary to have a leadership of Army Hospital that has visionary, transformative and militaristic leadership strategy to support hospital vision and mission.

b. Education and training leadership for prospective leaders of Army Hospital and also for the leadership of Army Hospital.

\section{Reference}

Bennis, W. (2009). On becoming a leader. Philadelphia, PA: Perseus Book Groups.

Buku Petunjuk Pengisian, Pengolahan, dan Penyajian Data Rumah Sakit. Depkes RI. (2005). Jakarta: Depkes RI.

Burns, J. M. (2003). Transforming Leadership. New York, NY: Grove/Atlantic.

Chang, T. Z., \& Su, J. C. (1998). Market Orientation, Service Quality and Business Profitability: a Conceptual Model ad Empirical Evidence. Journal of Service Marketing, 12. https://doi.org/10.1108/08876049810226937

Church, A. H. (1995). Linking Leadership Behavior to Service Performance; Do Manager make a Difference? Managing Service Quality, 5.

Kartono, K. (2016). Pemimpin dan kepemimpinan: apakah pemimpin abnormal itu? Jakarta: Rajawali Pers.

Rumkital, M. (2003). Informasi Pelayanan Rumkital Dr Mintoarjo. Edisi Ke Dua.Penerbit Universitas Indonesia UI-Press. Jakarta.

Suryadi, S. (2001). Biaya atau Kepuasan Pasien? www. Pdpersi.co.id

Wibowo. (2016). Manajemen Kinerja. Jakarta:Raja Grafindo Persada.

Yukl, G. (2001). Leadership in organization. New Jersey: Prentice-Hall.

Zeithaml, V. A., Leonard, L. B., \& Parasuraman, A. (1988). Communication and Control Processes in the Delivery of Service Quality. Journal of Marketing, 52. https://doi.org/10.2307/1251263

\section{Copyright Disclaimer}

Copyright for this article is retained by the author(s), with first publication rights granted to the journal.

This is an open-access article distributed under the terms and conditions of the Creative Commons Attribution license (http://creativecommons.org/licenses/by/4.0/). 